\title{
CULTURA VISUAL: UNA ALTERNATIVA DIDÁCTICA PARA LA EDUCACIÓN ARTIISTIICA
}

\author{
Esp. NORMA PIEDAD CASTELLANOS JOYA
}

\section{RESUMEN}

La imagen y en especial la imagen visual, domina nuestro mundo de hoy. Se nos impone querámosla o no - para bien o para mal. El desbordamiento de la imagen relacionada con el vertiginoso mundo de los objetos se ha convertido en elemento de investigación, pues el conocimiento de las imágenes, de su origen y de sus leyes es una de las claves de nuestro tiempo las cuales genera problemas de carácter descriptivo e interpretativo, ya que la polivalencia de significados y sentidos presentes en ella no acepta simplemente un único sentido, sino, se podría decir la totalidad de sentidos.

Desde esta perspectiva, las instituciones escolares no se encuentran preparadas para asumir el reto de la imagen al interior de las aulas, ni siquiera desde la Educación artística. Los resultados de esta investigación muestran que los estudiantes consumen a diario una diversidad de imágenes, sin embargo, carecen habilidades para verlas y observarlas, así como para leerlas, escribirlas, pero sobre manera, de la capacidad de hablar de las imágenes y sobre las imágenes que constituyen el mundo.

En este sentido, en palabras de Efland. Freedman y Stuahr la función de la enseñanza de la Educación Artística "es preparar a los estudiantes a comprender los mundos sociales y culturales en los que ellos habitan. Esos mundos son representaciones creadas con las cualidades estética de los medios" ${ }^{57}$. Por lo tanto, comprender no significa develar verdades ocultas en los mensajes que imponen las imágenes, ni transformar, debería ser entendido como provocar un cambio social como consecuencia del develamiento de tales verdades. Para tal fin, se hace evidente la necesidad de una metodología que permita obtener estas habilidades lectoras, escritoras y parlantes para ser dueños de esas imágenes, controlarlas o beneficiarnos de ellas, ya sea por el gozo o para el uso. Por tanto se requiere de la construcción de una didáctica de la visualidad que cimienta un nuevo tipo de pensamiento, en donde la imagen recobra un significado con relación al pensamiento verbal, lógico-discursivo dentro de los procesos de orientación pedagógica en los diferentes niveles escolares, desde los grados básicos hasta la universidad. El estudiante a través de la imagen construye el conocimiento explorando el mundo, el entorno y actúa sobre él sin esperar que todo se le dé. A partir de estos planteamientos la investigación realiza una propuesta básica a partir de la imagen como instrumento pedagógico de la cultura visual que contribuya a mejorar los procesos de descripción, análisis e interpretación en niños, niñas y jóvenes de las instituciones educativas ubicadas en la zona rural del departamento del Huila.

57 Read, Herbert. Educación por el arte. Ediciones Paidos Ibérica, colección: "PaidosEducador.pág 119 


\section{INTRODUCCIÓN}

Plantear la necesidad de acercar el estudio de la cultura visual a la escuela no responde a un esnobismo sino a una necesidad. No se trata de enseñar la Educación Artística, utilizando un nuevo concepto pero que en realidad es más de lo mismo, aunque ahora vinculado a la historia del arte, sino que, parafraseando a Debray, de lo que se trata es de explorar un campo de conocimientos mestizo sobre lo que podría contribuir a construir una Historia de la Mirada. Esto implica iniciar una historia sobre las historias que se cuentan y que ellos mismos cuentan) sobre los objetos artísticos y las manifestaciones culturales de tipo visual que se encuentran en el contexto.

En la educación escolar es necesario llevar a cabo esta empresa desde un cruce de miradas. Las del pasado y las del presente. Las que se reflejan y proyectan en las imágenes objeto y tema de investigación (siempre en grupo y en relación, nunca aisladas) de la época o la sociedad para tratar de organizar las diferentes miradas desde conceptos claves. Esto supone aceptar que los objetos no tienen vida, sino que adquieren sentido por la experiencia de quien los mira o los posee. Pero al mismo tiempo, los objetos son una fuente de conocimiento. Lo que reivindica nuestra propuesta curricular es la necesidad de investigar sobre estos objetos para aprender. En este sentido, en esta tesis se presentan los resultados de la investigación realizada en el Programa de Maestría en Educación, con orientación en diseño, gestión y evaluación curricular, cuyo objetivo se orienta a descubrir el impacto que tienen las imágenes como componente básico de la cultura visual en los estudiantes de la básica de la zona rural del municipio de la Plata-Huila, y particularmente los significados que se construyen en el espacio escolar alrededor de éstas, desde los referentes simbólicos y culturales de los estudiantes considerados aquí como el punto de partida en un proceso que busca la resignificación de los contenidos educativos propuestos oficialmente para las instituciones educativas en el campo de la Educación Artística y Cultural.

A partir de este objetivo general, se seleccionó la Institución Educativa rural Monserrate del Municipio de La Plata-Huila donde se realizó el trabajo de campo necesario para la construcción del referente experimental que sustenta la investigación.

\section{PLANTEAMIENTO DEL PROBLEMA}

Los niños y jóvenes se encuentran inmersos en la cultura de los medios tecnológicos, están formados con la dinámica de la televisión y asimilan fácilmente las formas de comunicación en red. Mediante su relación con las nuevas tecnologías tienen una singular capacidad cognitiva y son acreedores de un repertorio expresivo cuyo lenguaje les resulta fácilmente apropiable. Sus narraciones están signadas por el ritmo y la velocidad de las comunicaciones masivas y sus percepciones responden a la cultura de la pantalla. Según Jesús Martín Barbero, se trata de la formación de "comunidades hermenéuticas que responden a nuevos modos de percibir y narrar la identidad, y de la conformación de identidades con temporalidades menos largas, más precarias pero también más flexibles, capaces de amalgamar, de hacer convivir en el mismo sujeto, ingredientes de universos culturales muy diversos" Los jóvenes aplican su forma de vida a una lógica propia, acomodándose a nuevas formas de reunión cuyo eje es estar conectados, estar juntos sin más . 
Los jóvenes de la Institución Educativa Monserrate del centro Poblado Monserrate, del municipio de La Plata -Huila, no son ajenos a la cultura de la imagen. Cada vez son más productores y consumidores de imágenes y, paradójicamente, no responden a este esquema con el conocimiento y la reflexión que sería óptima en tal panorama.

La hiperrealidad consecuencia de un contexto poblado de imágenes con mayor fuerza que la realidad misma y partícipe del pensamiento postmoderno, creación de mundos paralelos, de fantasía (Disney, los Hanna Barbera...) o de interrelaciones "cíber-noviazgo). Un espacio en el que se está produciendo la denominada hiperestetificación , donde los valores relacionados con la estética, la imagen, prevalecen sobre otros valores no visibles, un espacio que dignifica la juventud, el poder adquisitivo, y donde los conceptos tradicionales de lo que es arte han de ser repensados haciendo referencia a la incidencia de los mass media, la pujanza de las tecnologías, la sociedad del espectáculo...

Sufrimos diversos terrorismos visuales -en palabras de María Acaso - y una analfabetización visual grave que nos hace víctimas propiciatorias de este mundo complejo: ante un contexto eminentemente visual y rodeado de referentes que precisan su decodificación.

Desde otra perspectiva, un aspecto importante dentro del planteamiento del problema estaría dado por la actitud de los docentes de Educación Artística frente a sus prácticas en el aula. Al respecto, ¿Cuáles son los objetivos, desde donde partir y hacia donde llegar para hacer de la Educación Artística un área de impacto en el currículo escolar? ¿El maestro fija metas e intenta de alguna manera arribar a ellas a través de sus prácticas pedagógicas? El Área de Educación Artística nos plantea múltiples actividades de aprendizaje, amplias, ricas y diversas, donde la imagen es el eje fundamental y que permanentemente ponen en juego la creatividad no sólo del estudiante sino también la del docente.

Los nuevos tiempos demandan que las instituciones educativas ofrezcan a niños, niñas y jóvenes una educación artística de calidad, lo que requiere disponer de medios, recursos y apoyos que generen condiciones ampliamente favorables para que se produzca el proceso de aprendizaje y se alcancen niveles óptimos de logro.

Existe en el argot popular la frase que dice" una imagen vale más que mil palabras" pero, paradójicamente hay que saber interpretar la metáfora, para poder encontrar esas mil palabras, es necesario saber leer e interpretar el contenido de la imagen y no llegar a ser como dice el viejo adagio "no tragar entero" y es aquí donde radica la importancia del presente proyecto, el cual propone desarrollar una visión crítica y reflexiva en los estudiantes para que no se conviertan en consumidores pasivos. Las imágenes afectan las visiones de los individuos, sobre ellos mismos y sobre el universo visual que les rodea y del cual se hace parte, en relación con la cultura y el contexto donde se desarrolla.

¿Cuál es el impacto de la imagen generada desde la cultura visual a los estudiantes de Educación Básica de la Institución Educativa Monserrate del centro Poblado Monserrate del municipio de La Plata-Huila? 


\section{FUNDAMENTOS TEÓRICOS}

\section{Arte y Educación Artística}

El reconocimiento que se otorga hoy a la Educación Artística en la formación básica ha cambiado de manera sustancial en comparación con otras épocas; actualmente se aprecia la importancia que tiene el arte en el desarrollo cognitivo de los estudiantes y en la construcción de significados de la realidad. Este cambio se debe a varios factores, entre ellos se puede mencionar la relevancia que tienen hoy los lenguajes artísticos como manifestaciones de la cultura, permitiendo la comprensión y apropiación del mundo de forma sensible, éste es un aspecto relevante para tomar conciencia sobre la condición del ser humano.

Es así como el aprendizaje y la enseñanza del arte tiene un espacio curricular en el tramo formativo de la educación básica, el cual abarca desde el nivel preescolar hasta secundaria. Con ello, se privilegia al arte como un saber fundamental que no puede estar ausente de la vida de los niños, niñas y de los jóvenes de nuestro país. Sin embargo, cabría preguntarnos ¿Qué significado se le da al arte?

Explicar lo que es el arte es una tarea compleja, pues pocas palabras encierran tantos sentidos y expresiones. A lo largo del tiempo se han dado múltiples definiciones sobre lo que es el arte. Ya los filósofos de la civilización griega, como Platón y Aristóteles, se preguntaron sobre la naturaleza y finalidad de la música, la poesía o la pintura, dando origen a las primeras teorías sobre el arte de las que se tiene memoria. Desde entonces y hasta nuestros días, no se ha dejado de discutir sobre cuestiones artísticas.

La razón de ser del arte se ha buscado entender en cada época y lugar, vinculándolo con la belleza, el placer, la representación del mundo, la espiritualidad, la originalidad, la crítica social, y una larga lista de nociones que constituyen un campo autónomo de la teoría del arte, llamada historia de las ideas y teorías estéticas. Hoy en día, los filósofos y críticos han dejado de buscar una definición comprehensiva del concepto "arte" (por considerarla una tarea imposible e inabarcable), y más bien se han enfocado en el estudio de la diversidad de sus manifestaciones y objetivos.

A pesar de ello, es posible delinear algunas características generales del arte. En primer término; y aunque parezca obvio, el arte es una actividad exclusivamente humana. La naturaleza, aún en sus manifestaciones más bellas o imponentes, no produce arte. Éste es un terreno intrínsecamente ligado a la humanidad, y por lo tanto, a la cultura. Al respecto Huyghe afirmaba que el "El arte y el hombre son indisociables. No hay arte sin hombre, pero quizá tampoco hombre, sin arte. Pero él, el mundo se hace más inteligible y accesible, más familiar. Es el medio de un perpetuo intercambio con lo que nos rodea, una especie de respiración del alma, bastante parecida a la física, sin la que no puede pasar nuestro cuerpo. El ser aislado o la civilización que no llegan al arte están amenazados por una secreta asfixia espiritual, por una turbación moral". Por lo tanto, "El arte utiliza la riqueza de su contenido para completar la experiencia que tenemos de nuestra vida exterior y para evocar sentimientos y las pasiones con el fin de que nuestra sensibilidad continúe abierta a lo que sucede fuera de nosotros.". 
El arte es también una actividad intencionada, es decir, responde a la necesidad de los seres humanos de comunicarse entre sí por medio de símbolos; empleando los recursos intrínsecos al cuerpo, la voz y el movimiento; o bien herramientas y materiales tomados de la naturaleza, con los que se producen obras o acciones con un sistema de significados. Desde esta perspectiva, son incontables las disciplinas que han abordado el problema de la procedencia del significado en las artes y especíícamente en las artes visuales. Artistas, historiadores del arte, filósofos y especialistas de diversos campos de las ciencias humanas y sociales han explorado durante largo tiempo cómo y qué "comunican" las artes visuales; por ejemplo, los psicólogos Gestalt han realizado algunos de los trabajos más interesantes en este campo, trabajos cuyo mayor interés reside en los principios de la organización perceptiva, del proceso de constitución de todos a partir de las partes.

El arte en la educación es un factor determinante en el proceso del desarrollo evolutivo, sensitivo e intelectual del estudiante, constituye un medio para comunicarse y expresarse en pensamientos y sentimientos. Por ello, cuando se imparte en el aula, se comienza a trabajar con la creatividad, la expresión y el desarrollo de la apreciación estética; elementos que logran integrar la personalidad del educando, y que, en sí mismos, pueden llegar a ser terapéuticos, ayudar a liberar tensiones y a proponer soluciones creativas en la vida cotidiana. Su objetivo fundamental es lograr el proceso creativo en la educación; esto resultaría de forma más objetiva si este proceso llevase un planeamiento teórico práctico en los doce años de educación básica y media; su importancia reside en la maduración de la personalidad del educando y considera un equilibrio en cuanto a pensamiento/cuerpo, razonamiento/ sensibilidad.

Enseñar entonces educación artística, es difícil porque es dejar aprender, incluso ayudar a desaprender, facilitar las condiciones para que broten las singularidades, ello supone propiciar espacios para pensar más allá de lo ya pensado, no tanto dar lecciones como sembrar un inquietud, la inquietud de sí. La educación artística debería asumirse como acto creador, como obra de arte, es decir -y para ser fiel a su objeto- sus procedimientos deberían desarrollarse como proceden los grandes artistas que transcurren por territorios aún no nombrados No se hace un curso sobre lo que ya se sabe, sino sobre lo que se busca, afirmaba GillesDeleuze, quien hizo de sus clases de filosofía un acto estético. También comentaba que le hubiese gustado dar clases a la manera de Bob Dylan, es decir organizarlas como una canción, con desarrollos previsibles pero donde la improvisación también pudiera entonar lo suyo. Una tensión entre lo preparado y la apertura a lo desconocido a trayectos insospechados, es decir una educación que tiene horizontes y que sabe perderlos pero que puede volverlos a retomar.

Por todo ello, la Educación Artística puede ser una educación que recupere del pasado las antiguas aspiraciones a la educación integral, la educación de todas las facetas y capacidades humanas, y que mire al futuro para proporcionar a los educandos las capacidades que la sociedad en continuo y presuroso cambio, donde el pensamiento creativo, la capacidad de aprender a aprender, la de saber buscar problemas y nuevas y múltiples soluciones para ellos o la preparación para tratar con la complejidad son factores muy valiosos. La imagen del educando que aparece como fin de esa educación no es simplemente la de un artista, 
sino la de un individuo artista de sí mismo, siempre en crecimiento, en proceso de desarrollo de todas sus capacidades, siempre en transformación en un mundo diverso, complejo y en continuo cambio. Una imagen, por tanto, que interesa a todos los individuos, tengan especiales dotes o intereses artísticos o no los tengan. sino que se busca analizar el contexto de ésa obra y su integración con su espacio circundante.

\section{CULTURA VISUAL}

Hernando Fernández asegura que cuando se busca una definición sobre la cultura visual se encuentra en el contexto una diversidad importante. Al respecto, se, Bryson, Holly y Moxy, hablan más de 'imágenes' que de 'arte'; Jenks se refiere a la cultura visual en términos de 'visualidad'; Bird la define como 'un análisis materialista del arte'; en Estados Unidos y Gran Bretaña se habla de cultura visual o estudios visuales; en Francia y Alemania, teoría de la imagen o ciencia de la imagen y Heywood y Sandywell se refieren a la hermenéutica de la experiencia visual'.

La cultura visual no solo reseña una serie de objetos, sino a un campo de estudio que ha ido emergiendo desde la confluencia de diferentes disciplinas, en particular desde la Sociología, la Semiótica, los Estudios culturales y feministas y la Historia cultural del arte, y que dibuja diferentes perspectivas teóricas y metodológicas. Este campo suele pensarse como formado por dos elementos próximos: las formas culturales vinculadas a la mirada y que se denominan como prácticas 'visualidad'; y el estudio de un amplio espectro de artefactos visuales que van más allá de los recogidos y presentados en las instituciones de arte.

Es importante ordenar las definiciones de cultura visual y no solo presentarlas, puesto que hay definiciones más políticas, como la Mirzoeff y otras más académicas como las de Walker y Chaplin. Unas son respuestas a los cambios en las disciplinas y sobre todo a la influencia del postestructuralismo en la Historia del Arte y los Estudios de los Medios y de Género como es el caso de Rampley, y otras son una forma de praxis para dotar y construir con los ciudadanos formas de resistencia ante el dominio de nuevas formas de representación homogeneizadoras y hegemónicas de la realidad y de uno mismo tal y como lo asegura Moxey , para generar las nuevas visualidades.

Para el caso, Mirzoeff explora cómo la visualidad ha llega a desempeñar un papel tan relevante en la vida moderna. Para llevarlo a cabo se requiere lo que Foucault denominó una genealogía de la cultura visual, que se proyecta en las trayectorias que conducen al estudio de las formas de visualidad contemporáneas, sin pretender agotar en esta empresa la riqueza y variedad del campo. De esta manera, en lugar de perseguir un objetivo de carácter enciclopédico, la cultura visual ha de aceptar su estatus cambiante y provisional, dada la constante formación - y reformulación- de los medios visuales contemporáneos y de sus usos y apropiaciones.

La cultura visual es el entramado de prácticas, tanto de representación como de acción, y de discursos, resultantes y condicionantes al mismo tiempo, del ejercicio de la visualidad como proceso de producción de significado cultural, que parte de la circulación pública de las 
imágenes. Como tal, a través de sus implicancias culturales, comunicacionales, epistemológicas y tecnológicas, dota de sentido a la educación como práctica social, constituyéndose en un contexto inevitable para la misma.

Culturalmente, la cotidianeidad de las relaciones humanas es transformada por la cultura visual, creándose una subjetividad diferente que se caracteriza por una nueva sensibilidad, más vivencial e inmediata, para percibir y narrar el mundo circundante. Se conoce a través de la experiencia. Al mismo tiempo, esta subjetividad establece nuevas relaciones de poder que cuestionan la forma de concebir la autoridad dentro de todas las esferas de la sociedad. La autoridad del maestro dentro de la escuela también se ve interpelada.

\section{METODOLOGÍA}

Para responder a la pregunta y a los objetivos del presente proyecto de investigación se aplicó un enfoque que se enmarca en el ámbito de las metodologías cuantitativa y cualitativa y más concretamente en el análisis de un conjunto de ideas y conceptos proporcionados por la población seleccionada. El propósito estaba orientado a conocer el impacto de la imagen en los estudiantes de la Institución educativa" Monserrate" de manera que nos permita descubrir la manera en la que éstos la leen y la interpretan para su comprensión.

Desde esta perspectiva, en investigación se propuso desarrollar un proceso de tipo exploratorio, lo que permitió precisar el tipo de imágenes que consumen los estudiantes y el nivel de análisis e interpretación de las mismas. En tal sentido, con el enfoque investigativo se procuró abordar la situación global del ámbito educativo del área de Educación Artística y cultural con el fin de propiciar una propuesta de innovación en el campo de la didáctica del área en mención dirigido al contexto rural.

\section{Población y muestra}

- Universo: Instituciones Educativas Publicas del Municipio de la Plata-Huila. El municipio cuenta con 19 instituciones educativas públicas tanto en la zona rural como en la zona urbana.

- Población: La población abarca la comunidad educativa rural de la institución educativa Monserrate del Municipio de La Plata, compuesta por 696 estudiantes de cuatro sedes, en donde tres de ellas son de básica primaria y la cuarta es la sede principal de bachillerato.

- Muestra: En toda investigación es necesario identificar y procesar los sujetos u objetos de estudio por lo cual es imprescindible definirlos de manera apropiada, según Tamayo asume la población como"la totalidad del fenómeno a estudiar en donde las unidades de población poseen características comunes, la cual se estudia y da origen a los datos de la investigación". En el presente estudio, la población está conformada por 89 estudiantes de los grados quintos a undécimo de los cuales un 55\% de estudiantes son de sexo femenino y un $45 \%$ está conformada por estudiantes de sexo masculino quienes oscilan entre los 10 y 18 años de edad. 
El primer criterio de selección muestral estuvo determinado por la edad y el nivel escolar. Por lo tanto se seleccionaron estudiantes a partir del grado quinto hasta el grado undécimo. Una vez cumplido este criterio, la muestra de informantes debía ser lo suficientemente heterogénea como para poder observar patrones comunes así como diferentes frente a la lectura, análisis y comprensión de la imagen.

\section{Técnica e instrumentos}

La investigación emplea técnicas e instrumentos que resultan fundamentales en la recogida de datos propios de la investigación cuantitativa y cualitativa, que permiten la organización y procesamiento de la información, necesarios en el análisis y la interpretación. Las técnicas e instrumentos se emplean de manera flexible y se utilizan en la medida que resulten efectivos en la recolección de la información. Dado que, "la información que se busca es aquella que más relación tenga y ayude a descubrir mejor las estructuras significativas que dan razón de la conducta de los sujetos en estudio" Martínez. Por lo consiguiente, las técnicas utilizadas para la recolección de datos en esta investigación son: las notas de campo, la encuesta y el análisis documental.

- Notas de campo: Como método de investigación analítico, la observación participante depende del registro de notas de campo completas, precisas y detalladas. Se deben tomar notas después de cada observación y también después de contactos más ocasionales con los informantes, como por ejemplo encuentros casuales y conversaciones informales. También deben tomarse notas durante la etapa previa al trabajo de campo. Siempre deben ser lo más completas y amplias posibles.

- Encuestas: En la investigación, se aplica la encuesta, la cual es para Sierra "la obtención de datos de interés mediante la interpretación a los miembros de la sociedad" . La encuesta, como instrumento metodológico representa la búsqueda de información de manera planificada y dirigida a las personas relacionadas directamente con la problemática detectada. En tal sentido, la encuesta permite estudiar el objeto de estudio de forma integral, tratando de descubrir la realidad existente, adquiriendo los criterios, actitudes y comportamientos de los participantes.

- Análisis documental: Se focalizó en la revisión de los Planes Educativos institucionales (PEI) y las programaciones del área de educación artística, en donde se tuvo en cuenta la metodología, los contenidos, las actividades, los recursos y la evaluación. También se revisaron los cuadernos de los estudiantes para saber que tienen consignado y de allí realizar el análisis, también se tienen registros fotográficos de las imágenes que más les gusta.

\section{DISCUSIÓN}

Actualmente, se observa cómo las imágenes "conquistan"la escuela, pero la dificultad no es el hecho que entre a los espacios escolares sino, señalar la utilidad pedagógica que presta, porque si bien es cierto, las imágenes permiten desde fijar el sentido de las palabras en los métodos de lectura, hasta ilustrar moralmente a los estudiantes. 
Los resultados finales al aplicar los instrumentos en este proyecto muestran una clara necesidad en los niños, niñas y jóvenes de la institución Educativa Monserrate del municipio de la plata, Huila. De dejar como apoyo una propuesta pedagógica que les ayudara a comprender mejor su concepto sobre el arte, a lograr darle una interpretación a cada imagen que observan, a analizar las imágenes dándole una interpretación y siendo cada vez más críticos y reflexivos a la hora de consumir los diferentes tipos de imágenes, para que con esto no se de en ellos ese famoso adagio que dice "No tragar entero"

\section{PROPUESTA DIDÁCTICA}

TITULO: La cultura visual en la zona rural: una propuesta alternativa para el Centro Poblado Monserrate del Municipio de la Plata.

\section{Propuesta Didáctica}

Actualmente, el lenguaje visual posee un poder tan o más extenso que el lenguaje verbal, sin embargo, seguimos en la tónica repetitiva de ejercicios basados en el prácticas tradicionales, sin pensar en alfabetizar visualmente a nuestros estudiantes de manera activa. No interesa al sistema en el cual estemos inmersos, pero si interesa que los individuos se formen como lectores de imágenes activos, que no solo las puedan decodificar, sino también relacionarlas, juzgarlas y criticarlas. Por lo tanto urge una propuesta que involucre la imagen como recurso didáctico en el aula.

Desde la inclusión de imagen como recurso didáctico, proviene el desafío al que los profesores tienen que hacer frente en sus clases, y que consiste en comprometerse con las imágenes y la tecnología del mundo postmoderno sin rechazar el análisis cultural, el juicio moral y la reflexión que las imágenes amenazan con suplantar en la actualidad. Para ello se podría tener en cuenta el papel o uso que los estudiantes realizan de las estrategias de comprensión de los elementos de la cultura visual. El predominio de cada una de ellas ayudará a situar al docente en relación con un aspecto del desarrollo de la comprensión de los estudiantes.

Señala Efland que profesores y alumnos deben colaborar para la construcción de nuevos significados fuera de la experiencia fragmentaria de las disciplinas escolares desarrollando enfoques curriculares que abarquen disciplinas que caen fuera de competencias tradicionales de la educación artística. En consecuencia, y de acuerdo a la propuesta por Eflan en el texto Educación en el arte posmoderna el currículo debe contener una estructura parecida a un entramado en red, muy parecida en cierto modo al modelo de entorno social con el que está cada vez más familiarizado el escolar. La estructura en red invita a niños, niñas y jóvenes a buscar.

Abordar el estudio de la imagen hoy implica abrirse al abanico de posibilidades que los medios han aportado tanto para su estudio como para el tratamiento de su producción reconociendo su multiplicidad tanto técnica como significativa. Por lo tanto, y de acuerdo a las necesidades de los y las estudiantes de la educación básica de la Institución Educativa Monserrate de la zona rural del municipio de La Plata-Huila, se pretende profundizar en el asuntos de la pedagogía de la imagen en donde el eje curricular en el campo de la Educación Artística será fundamentado a partir de la cultura visual. 


\section{CONCLUSIONES}

Al finalizar el análisis de los datos recogidos de las niñas, niños y adolescentes de la institución educativa Monserrate, del centro poblado Monserrate de la zona rural del municipio de La Plata-Huila, cuya finalidad fue explorar y conocer el tipo, la procedencia y las características de las imágenes que consumen a diario los estudiantes de quinto a undécimo grado de la Institución Escolar Monserrate, y en cumplimiento de los objetivos planteados, se puede afirmar que los estudiantes de la zona rural al igual que los de zona urbana están inmerso en el mundo de la imagen, pero sobre todo de aquellas imágenes que el mundo de los medios y el contexto les ofrece.

Es claro que las imágenes que ofrecen los medios y se enfrentan niños, niñas y jóvenes de la institución educativa, lejos de ser imágenes inocentes e inconscientes, tienen múltiples capas de significados que necesitan ser deconstruidas para ser analizadas, comprendidas y utilizadas de manera creativa. La imagen ha dejado de ser una simple ilustración de un texto o diálogo para convertirse en un gran instrumento que ofrece enormes posibilidades en el aprendizaje en todos los campos del conocimiento. Sin embargo, se observa que un número significativo de docentes de la institución Monserrate en poco o nada utilizan la imagen como recurso didáctico en el aula, desaprovechando el gran potencial para el desarrollo de estrategias de expresión gracias a su capacidad para producir reacciones, sensaciones o recuerdos en el receptor de las mismas.

Los medios masivos son espacios significativos por los estudiantes y de los cuales se apropian de las imágenes son un importante recurso de la socialización que impactan sobre el proceso de los jóvenes e influye en la creación de sus imaginarios, identidades y valores. Los medios que ellos consideran más significativos son la televisión, el dvd, las revistas y el internet, medios que tienen el poder y la influencia en la transformación de la cultura moderna, marcan y originan como dimensión importante el ambiente familiar, social, escolary cultural, estos medios facilitan la satisfacción de algunas de sus necesidades, pero también, introducen cambios negativos que por supuesto le afectan su comportamiento.

De otra parte, se pudo determinar que los estudiantes de la institución educativa Monserrate reconocen en el paisaje, la escuela y el pueblo imágenes representativas que son utilizadas como referentes en las diferentes áreas del conocimiento y específicamente en las clases de educación artística, sin embargo, son utilizadas como un referente estereotipado, poco significativo dentro del contexto educativo como una identidad proyectiva y aglutinante que actúa activamente sobre los procesos de construcción de las identidades y subjetividades.

La imagen está ahí, en cada contexto, no es elegida por nadie, desde el mundo de los expertos se considera y se muestra en el contexto que ellos consideran, el artista, el autor, la autoría no aparece, la trayectoria tampoco, el significado y la intencionalidad tampoco, todo se centra en la imagen resultado, el objeto visual. En la conexión entre imagen y educación hayamos un vínculo, relativamente joven, la educación artística, como referente académico más sólido de área de conocimiento de la imagen. Esta área de conocimiento como disciplina, tiene sus propios problemas de identificación y localización originados, de un lado por la propia práctica educativa y sus modos de hacer en este contexto y de otro, por la 
problemática de lo artístico y su experiencia. Sin embargo, es evidente que la imagen siendo el objeto fundamental de la educación artística, en la instituciones educativas en general aún no vinculan la imagen generada desde la cultura visual al interior de las aulas escolares.

Atendiendo a los datos arrojados a través de la encuesta realizada a los estudiantes de la institución educativa Monserrate, se observó que el nivel de apreciación, análisis e interpretación los estudiantes no han recibido las herramientas necesarias para leer, interpretar y comprender una imagen ya sea verbal o no verbal. Las imágenes son siempre signos de algo ajeno que incorporan diversos códigos comunicativos, algunos muy específicos, como el código gráfico o el de relación compositiva entre los elementos que forman la imagen. Para leer de forma comprensiva y crítica las imágenes es necesario conocer estos códigos, lo que significa un cambio en las prácticas educativas de los docentes, para de esta manera, no seguir produciendo en masa niñas, niños y jóvenes que ignoren la nueva sintaxis de una nueva cultura visual, la cual es imposible ignorar desde los diferentes contextos.

La cultura visual, se propone una educación participativa e interactiva. Que desarrolle el espíritu crítico, el interpretativo del sentido de las cosas, los significados del mundo que nos rodea, para poder hacer frente a todo el cúmulo de mensajes visuales cargados de todo tipo de contenidos, enaltecedores unos y distorsionadores los otros. Para ello se hace necesario desarrollar la creatividad para una inserción activa en el mundo visual contemporáneo.

Desde esta perspectiva y después del análisis de la presente investigación, urge la necesidad de educar la mirada de niños, niñas y jóvenes de la institución educativa Monserrate del centro poblado Monserrate del municipio de la Plata-Huila, para que no continúen "tragando entero". La construcción de una nueva forma de ver, leer, decodificar, es abrir la educación hacia procesos de análisis y crítica que lleve a la práctica de la interpretación. Para dejar de ser meros receptores pasivos, reactivos a los estímulos, sino la de ser verdaderos intérpretes del ámbito profundo de lo que se está transmitiendo por esta vía.

La imagen actúa sobre nuestro universo mental en el que conservamos una serie de relaciones emocionales entre escenas y sentimientos, entre emociones e imágenes, Así, éstas se cargan de connotaciones que surgen del mundo interior de cada persona, ya que la imagen es polisémica, por la diversidad de sugerencias posibles que encierra. Es un vehículo privilegiado del pensamiento y la cultura y una valiosa herramienta para transmitir información.

\section{RECOMENDACIONES}

Se plantea a partir el desarrollo de esta propuesta la necesidad de acercar el estudio de la cultura visual a la escuela, no como un esnobismo sino como una necesidad. Se trata de un aprendizaje de la Educación Artística, utilizando la imagen como recurso, lo que permitirá explorar un campo de conocimiento inexplorado en las aulas escolares; esto implica, iniciar un proceso de alfabetización visual que permita la lectura y comprensión de los objetos artísticos y las manifestaciones culturales de tipo visual. 
A partir del desarrollo de este proyecto, se recomienda a los docentes de las distintas instituciones educativas replantear sus prácticas pedagógicas a la hora de enseñar las distintas disciplinas y especialmente al docente del área de educación artística, ya que es claro que el joven de hoy vive inmerso en el mundo de la imagen, por lo tanto, educar a través de la imagen implica un cambio en las prácticas de los docentes.

\section{REFERENCIAS BIBLIOGRÁFICAS}

- ACASO, María. La educación artística no son manualidades, Nuevas prácticas en la enseñanza de las artes y la cultura visual. Madrid: 2009.

- ACASO, María. El lenguaje visual. Editorial Paidós. Barcelona 2006

- BARBERO, J Martin. "Jóvenes, comunicación e identidad" en pensar Iberoamérica/Revista de cultura http://www.campusoei.org/pensariberoamerica/ric00a03.htm8

- BAUDRILLARD J.Cultura y simulacro, Kairos, Barcelona. 1989

- BAUDRILLAR, J. La ilusión y la desilusión estéticas. Caracas, Venezuela: Monte Ávila Editores Latinoamericana, C.A. 1998

- FERNANDEZ, Hernando. De qué hablamos cuando hablamos de cultura visual?. Revista educación y realidad. Julio 10 de 2005

- HUYGHE, Rene. El arte y el hombre. Planeta Barcelona 1977

- JIMÉNEZ. José. Teoría del arte. Madrid, Tecnos Alianza Editorial. 2002

- MIRZOEFF, N (2003). Una introducción a la cultura visual. Barcelona. Paidos. Citado por Hernández Reséndiz Arturo Leonardo en Dilucidando la cultura visual. Ensayo Marzo 19, 2009, 9:17 pm. Archivado.

- MARGULIS, M. y URRESTI, M. (2000). "La juventud es más que una palabra" en Ensayos sobre cultura y juventud. Buenos Aires: Biblos. Pág 65

- RAMPLEY, Matthew. La amenaza fantasma: ¿La Cultura visual como fin de la Historia del arte? En J.L. Brea (Ed.) Estudios visuales. La epistemología de la visualidad en la era de la globalización. Madrid: Akal, 2005b, p. 39-57.

- READ, Herbert. Educación por el arte. Ediciones Paidos Ibérica, colección:"Paidos Educador. Pág 88 
